\title{
Impact of Wetting and Drying Cycles on the Mechanical Properties and Microstructure of Vegetation-growing Concrete
}

\author{
Xiaole Huang*, Wennian Xu*†, Yu Ding*, Dong Xia**, Shiyuan Xiong*, Daxiang Liu* and Bo Pan* \\ *College of Civil Engineering and Architecture, China Three Gorges University, Yichang Hubei Province, 443002, China \\ **College of Hydraulic \& Environmental Engineering, China Three Gorges University, Yichang Hubei Province, \\ 443002, China \\ †Corresponding author: Wennian Xu; xwn@ctgu.edu.cn
}

Nat. Env. \& Poll. Tech.

Website: www.neptjournal.com

Received: $22-10-2020$

Revised: $17-12-2020$

Accepted: 22-01-2021

\section{Key Words:}

Vegetation-growing concrete Wetting and drying cycles Structural damage

\begin{abstract}
Vegetation-growing Concrete (VC), as a new type of cemented soil, is usually used for plants growing on the surface of high and steep rocky slopes. With the widespread application of VC substrate, a pressing problem arises to ensure its durability under wetting and drying conditions. To explore the greatest possible impact on the mechanical properties and microstructure features of VC substrate, an experimental program including triaxial test, SEM analysis, and ultrasonic testing was implemented. The results showed that wetting and drying cycles can significantly decrease more than 40-percent of peak strength, 60-percent of residual strength, and 50-percent of cohesion for VC substrate under ultimate conditions. The fundamental cause of reduction in mechanical performance was found to be the weakening of the bond between soil particles. And it was discovered that structural damage increased as the number of wetting and drying cycles increased but at a slower rate. Based on the tested results, linear functions between the loss extent parameters of mechanical performance and the structural damage variable were established for the VC substrate. Finally, the action mechanisms of wetting and drying cycles for VC substrate were discussed, and the main influential factors were proposed.
\end{abstract}

\section{INTRODUCTION}

Traditional cemented soils are artificially improved soil made by natural soils and cement. The cement added can improve the mechanical properties of natural soils and make the newly cemented soil meet higher load requirements (Hayano et al. 2013). VC substrate, developed by China Three Gorges University (Xu \& Wang 2001), is made of natural soil, cement, organic materials, and Amendment of Habitat Material (AHM), and can be regarded as an ecological cemented soil. This ecological cemented soil provides a number of advantages, including good caking properties for maintaining the integrity of the VC substrate and rock mass, as well as optimal conditions for plant growth. In recent years, VC substrate has been widely used for ecological restoration of high steep rock slopes in China and has achieved satisfying ecological and social benefits (Liu et al. 2018).

The essential criterion for VC substrate to attach to a sloped surface and be used as a plant growth substrate is durability. As a new material in environmental engineering, VC substrate is constantly exposed on the ground, and its endurance is affected by climate conditions. Among them, the wetting and drying cycle is one of the most common climate actions during periods of frequent rainfall and high temperatures. Numerous studies have investigated the influences of wetting and drying cycles on the mechanical properties of various types of soils. In general, natural soil is not durable under wetting and drying cycles. The strength can be reduced gradually with the increasing times of the cycles and reach the lowest level within 3 5 cycles (Pineda et al. 2014, Sayem et al. 2016).

Engineers and researchers are devoted to the development of all types of soil improvement technology to improve the engineering properties of natural soil. Among them, cement stabilization technology is one of the alternative solutions and has been extensively used in traditional engineering, for instance, subgrade engineering. The cement content is crucial in determining the improvement of mechanical properties under wetting and drying cycles. Zhang (2018) and Wang et al. (2018) showed that the strength of cemented soil with less than $10 \%$ cement decreased with wetting and drying cycles, while for cemented soils with more than $10 \%$ cement, it was found that the strength increased first and then decreased. However, no matter whatever the amount of cement is, the strength of cemented soils will eventually be 
reduced, reaching a minimum value, as long as the times of wetting and drying cycles are large enough. In other words, there is a minimum value for wetting and drying cycle times, wherein the mechanical properties of soil are most affected by wetting and drying cycles (Zhang et al. 2014). The number of the minimum cycles was found to be about 5 times for cemented fine-grained soil (Yu 2012, Tan \& Chen 2014), and the number for cemented sand seems much bigger, for instance, 12 times, as reported by Wang et al. (2017).

From the above studies, the reduction in mechanical properties of cemented soil during wetting and drying cycles is found to be highly dependent on the quantity of cement used and the type of soil. VC substrate is a new type of ecological cemented soil with specific components, but there is limited information available about the influences of wetting and drying cycles. The objective of this research is to evaluate the mechanical properties under the most serious situations of wetting and drying cycles, meanwhile, analyzing the change features of their microstructures, and pointing out the inner relationship between macro-mechanical performance and the microstructure.

\section{MATERIALS AND METHODS}

Materials: Planting soil, cement, organic materials (airdried sawdust in this study) and the AHM are four basic materials of VC substrate in the tests. The planting soil used was yellow-brown soil collected from the shallow surface of the earth in Yichang of Hubei, China. The soil was then air-dried and broken into pieces to pass through $2.0 \mathrm{~mm}$. The air-dried moisture content of the soil was $1.93 \%$ and the specific gravity was 2.65 . The cement used was composite Portland cement (P.C. 32.5) with a specific gravity of 3.1. The air-dried sawdust used had a moisture content of $5.80 \%$, and the density of its solid particles was $0.54 \mathrm{~g} . \mathrm{cm}^{-3}$, which was equal to the average density of commonly used woods in China. The AHM is made of mineral powders containing iron, phosphorus, calcium, and silicon as main materials, and water-retaining agents, and compound fertilizer as auxiliary materials.

By weight of air-dried planting soil, the amount of cement, sawdust, and AHM in VC substrate were 8\%, 6\%, and $4 \%$, respectively; their volumetric ratios were $6.97 \%$, $28.35 \%$, and 3.74 percent, respectively. From the mixture proportion, we know that planting soil and sawdust are the two main compositions of VC substrate. Based on the data of particle size distributions of planting soil and sawdust, the exact particle size distribution of VC substrate was calculated, as shown in Table 1 and Fig. 1. It is necessary to explain that during the calculation, cement and AHM particles were included in the " 0.074 " particles category. According to the China Standard for Engineering Classification of Soil, GB/T 50145-2007, the VC substrate was classified as cemented sand with a low proportion of fine-grained soil.

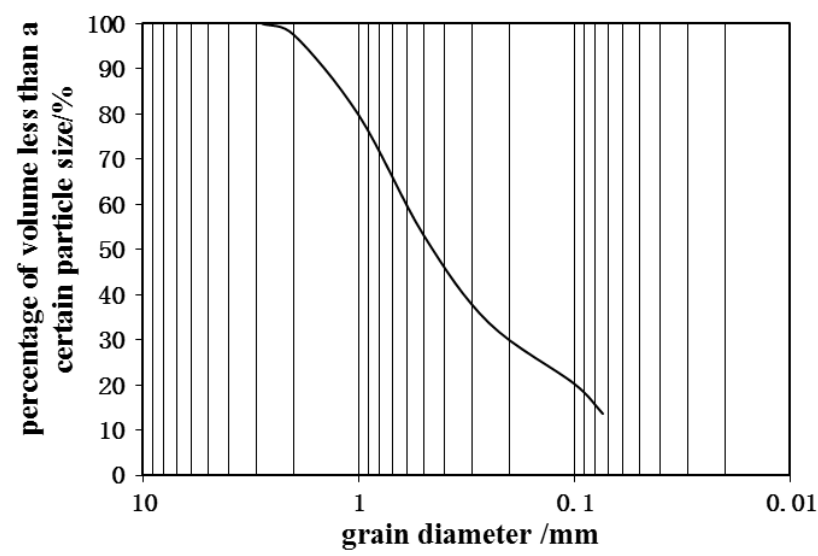

Fig. 1: Grain distribution curve of VC substrate.

Table 1: Particle size distributions.

\begin{tabular}{|llllllll|}
\hline Particle size $(\mathrm{mm})$ & $2.8-2$ & $2-1$ & $1-0.5$ & $0.5-0.25$ & $0.25-0.1$ & $0.1-0.074$ & $<0.074$ \\
\hline Planting soil & - & 21.34 & 25.46 & 19.88 & 16.88 & 8.17 & 8.27 \\
Sawdust & 12.08 & 12.03 & 40.74 & 24.76 & 7.04 & 3.34 \\
VC & 2.46 & 17.80 & 26.61 & 19.34 & 13.57 & 6.56 \\
\hline
\end{tabular}


The XRD spectrum of VC substrate was studied by using DY2198 XDR equipment. The tested XRD spectrum and the mineral compositions are shown in Fig. 2 and Table 2, respectively.

Preparation of Samples: Batches of VC samples were prepared with an initial water content of $20 \%$ and a dry density of $1.35 \mathrm{~g} . \mathrm{cm}^{-3}$. First, the four basic materials of one single sample were mixed in a container for more than $3 \mathrm{~min}$. Water was then added into it, after standing for another $3 \mathrm{~min}$, this mixture was stirred again to obtain a uniform distribution of moisture. The final mixture was then compacted into standard samples which were $80 \mathrm{~mm}$ in height and $39.1 \mathrm{~mm}$ in diameter according to the China Standard for Geotechnical Testing Method, GB/T 50123-2019. Finally, the standard samples were kept in an air-conditioned room at $25 \pm 2^{\circ} \mathrm{C}$ and relative humidity of $>90 \%$ for 7 days.

Wetting and Drying Cycles: The vacuum saturation method and drying method were applied for wetting and drying, respectively. The samples were first flooded with water for 48 hours and then were placed into a drier for drying for 12 hours. The temperature for drying was set at $45-55^{\circ} \mathrm{C}$ to simulate ambient temperature that $\mathrm{VC}$ substrate may encounter under strong sun in summer. The combination of one wetting and the subsequent drying process was referred to as one wetting and drying cycle. At the end of one cycle, samples were allowed to cool slowly at laboratory temperature and then flooded with water for the next cycle.

Samples were divided into four groups and marked as WDC0, WDC5, WDC10, and WDC0-10. Among them, WDC0 corresponded to the control substrate without wetting and drying cycles; From the viewpoint of practice, VC substrate would turn into a root-soil composite gradually with plants growing after the project finished. To evaluate the worst effects on VC substrate by wetting and drying cycles, the root effect in the early growth stage was ignored. And the WDC10 substrate, which was considered as the most serious state by wetting and drying cycles was treated by 10 times of the cycle. WDC5, with 5 times wetting and drying cycles, could be considered as an intermediate sample between WDC 0 and WDC10. WDC0-10 was prepared to measure the acoustic velocity of $\mathrm{VC}$ substrate with $0 \sim 10$ times treatment of wetting and drying cycles.

Testing Program: Three kinds of testing methods were used: triaxial test, SEM test, and ultrasound velocity test.

The instrument used for the triaxial test was a TSZ302.0 automatic strain-controlled tri-axial shear apparatus

Table 2: Mineral composition.

\begin{tabular}{|lllllll|}
\hline Composition & Quartz & Albite & Illite & Calcite & Montmorillonite & Dolomite \\
Mass fraction $(\%)$ & 56 & 14 & 10 & 9 & 8 & 3 \\
\hline
\end{tabular}

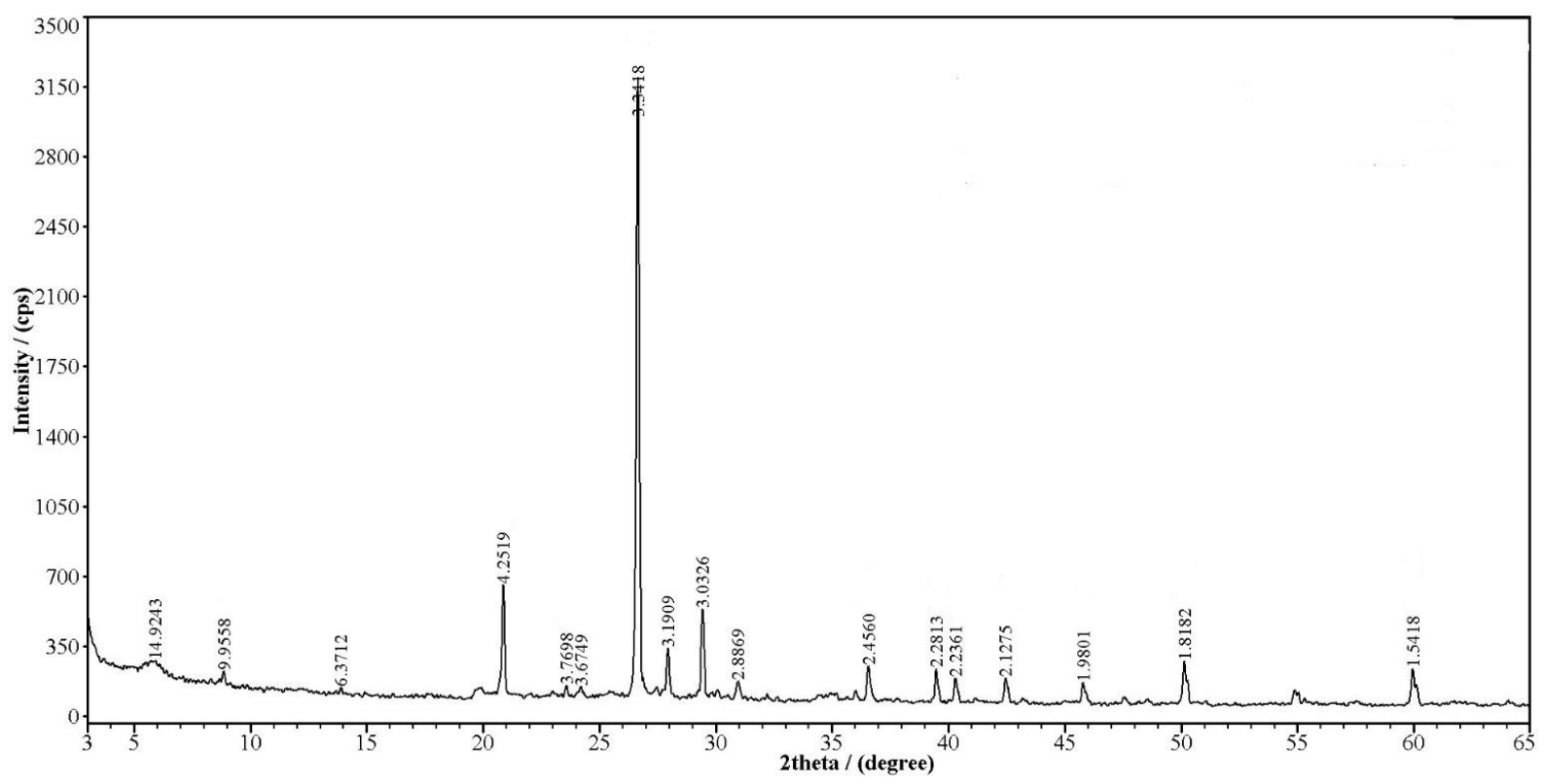

Fig. 2: X-ray powder diffraction spectrum of VC substrate. 
developed by Nanjing Soil Instrument Co., Ltd. (China). An unconsolidated, undrained triaxial method was taken and the confining pressures were 10, 30, and $50 \mathrm{KPa}$. During the test, the strain rate was fixed at a big rate of $4.5 \mathrm{~mm} . \mathrm{min}^{-1}$ as some researchers have reported that shear rates influence on soil structure can be neglected when normal stress in the test is low (Yang et al. 2014). The maximum deviator stress corresponding to the stress-strain curve was taken for the peak strength and deviator stress at the axial strain of $15 \%$ was taken for the residual strength. A JSM-7500F Cold Field Emission Scanning Electron Microscope (produced by JEOL) was used for the SEM test to analyze the microstructure of the substrate. The soil specimen, with dimensions of $5 \mathrm{~mm} \times 5 \mathrm{~mm} \times 2 \mathrm{~mm}$, was cut off in the middle section of the standard cylinder sample and was scanned under the amplification of 500 times and 1000 times. The instrument used for the acoustic velocity test was Nonmetal Ultrasonic Detector, model ZBL-U510. The test voltage was set at $500 \mathrm{~V}$; the sampling time interval was $0.4 \mu \mathrm{s}$. To improve the sample-transducer contact and enhance the measurement accuracy or stability, the transducer surface of the detectors was evenly coated with Vaseline before testing.

\section{RESULTS AND DISCUSSION}

Characteristics of Strain-Stress Curves: The stress-strain curve of the WDC0, WDC5, and WDC10 substrate under confining pressures of 10, 30, and $50 \mathrm{KPa}$ are shown in Fig. 3.

These curves have a similar variation trend which could be divided into four stages: compaction stage, elasticity stage, yielding stage, and softening stage. Taking curves at $10 \mathrm{KPa}$ for example, it can be seen that there are some differences in the curves of the substrate with different wetting and drying cycles. For the substrate WDC10, which had experienced 10 wetting and drying cycles, the axial strain in the compaction stage was higher than that of the control substrate WDC0 at the same deviator stress; the axial strain of the intermediary substrate WDC5 was between the substrate WDC0 and
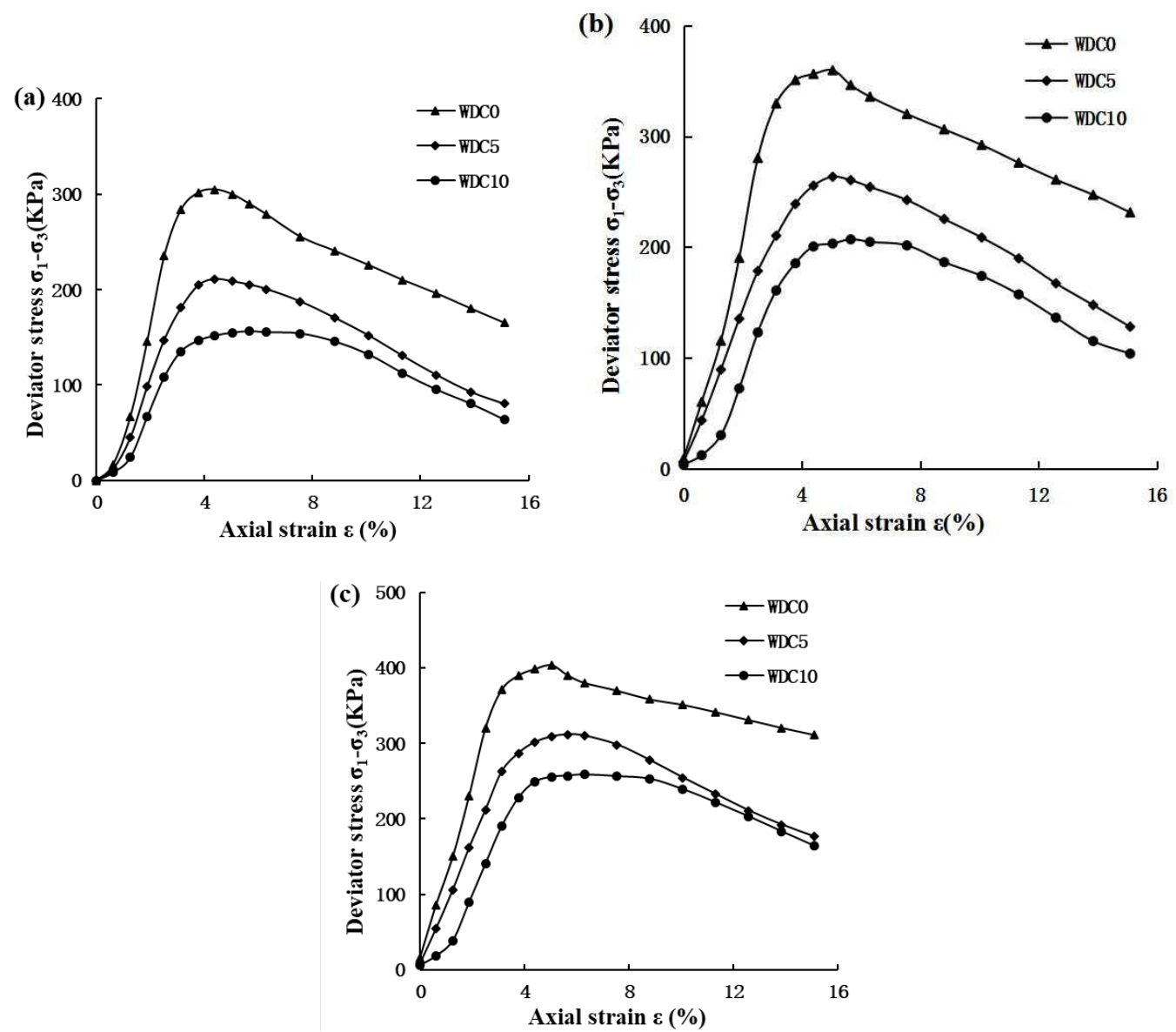

Fig. 3: Stress-strain curves of VC substrate. (a) $10 \mathrm{KPa}$; (b) $30 \mathrm{KPa}$; (c) $50 \mathrm{KPa}$. 
WDC10. The initial slope in the elasticity stage, the deviator stress in the yielding stage, and softening stage of the WDC10 were lower than that of the WDC0, and those of the WDC5 substrate was still somewhere in between. Similar results can be observed at confining pressure of 30 and $50 \mathrm{KPa}$. These results indicate that wetting and drying cycles lead to negative effects on the mechanical properties of VC substrate. And these effects indicate the link between times of wetting and drying cycles and mechanical properties.

For the same times of the cycles, the compacted behaviors of $\mathrm{VC}$ substrate were weakened to some extent when confining pressure increased up to $50 \mathrm{KPa}$; but the deviator stress showed an increasing trend with confining pressure. These beneficial effects of the enhancement in deformation property and increase in strength are mainly due to the lateral restraining of confining pressure, as being described in various studies. Despite the effects of confining pressure, we won't further discuss the confining pressure impact on VC substrate for two reasons. First, this research mainly focused on the effects of wetting and drying cycles, not confining pressure. Second, VC substrate is a kind of topsoil with only $10 \mathrm{~cm}$ in thickness, the confining pressure difference is low and far less than that used in current tests.

Strength Behaviors: Fig. 4 shows the peak strength and residual strength of the substrate WDC0, WDC5, and WDC10 under 10, 30, and 50KPa confining pressure. It is shown that for a given confining pressure, there are great differences among the three substrate samples in peak strength and residual strength, though their sequences of peak strength and residual strength were the same as the deviator stress mentioned above.

Compared with the control WDC0, the peak strength of the substrate WDC5 decreased by $30.8 \%, 26.8 \%$, and $22.8 \%$ at confining pressure of 10,30 , and $50 \mathrm{KPa}$, while for the substrate WDC10, it decreased by $48.7 \%, 42.5 \%$, and $40.0 \%$. As for residual strength, the declines of the substrate WDC5 and WDC10 were much higher than that in peak strength. Take the case of $10 \mathrm{KPa}$ confining pressure as an example, the residual strength of the substrate WDC5 and WDC 10 decreased by $51.4 \%$ and $61.4 \%$, about $20.6 \%$ and $12.7 \%$ higher than that of peak strength, respectively. These results show that wetting and drying cycles can decrease the strength of VC substrate by up to $50 \%$ of peak strength and $60 \%$ of residual strength. The results also indicate that the reduction of peak strength in the first five cycles was higher than that in the second five cycles, implying that effects by wetting and drying cycles gradually weakened as the cycles continued.

The cohesion and friction angle of the three substrate samples were calculated according to the data of peak strength at 10,30 , and $50 \mathrm{KPa}$ confining pressure. The results are listed in Table 3. It can be seen from the figure that the decline of cohesion for the substrate WDC5 and WDC10 were $34.0 \%$ and $54.0 \%$, respectively, which is similar to the results of the data of peak strength. However, there was no effect on friction angle. Obviously, the impact of wetting and drying cycles on the macro-strength of VC substrate was mainly the weakening of bonding properties.

Table 3: Cohesion and friction angle.

\begin{tabular}{|llll|}
\hline Sample code & WDC0 & WDC5 & WDC10 \\
\hline Cohesion $\mathrm{C}(K P a)$ & 75.39 & 49.72 & 34.69 \\
Friction angle $\psi\left(^{(}\right)$ & 33.63 & 33.86 & 34.00 \\
\hline
\end{tabular}
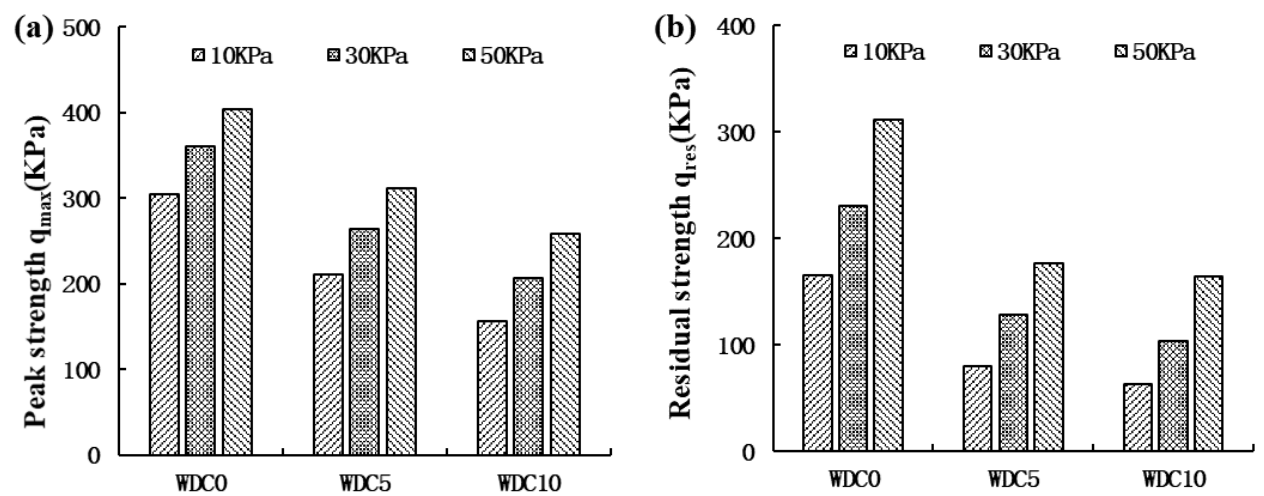

Fig. 4: Peak strength and residual strength of VC substrate. (a) peak strength; (b) residual strength. 
Structural Damage: Fig. 5 shows the SEM micrographs of the substrate WDC0, WDC5, and WDC10. As shown in Fig. 5(a), the substrate WDC0 represents a relatively dense matrix with good integrality. This matrix has few pore spaces, which are scattered randomly, and almost has no visible cracks.

Compared with the WDC0, the substrate WDC5 had more pore spaces and poor integrality. The pore spaces were bigger in size and mainly distributed in the interface between skeleton solid particles and debris particles as well as in the debris particle collection region. The biggest pore space of the WDC5 was almost double in size of that in the WDC0 substrate. Additionally, cracks can be observed in the edge of some skeleton particles within the scope of this micrograph. Overall, the substrate WDC5 (Fig. 5(b)) can be considered as a matrix with a partial cementation structure. Unlike the substrate WDC0 and WDC5, the WDC10 resembles a loosen matrix with poor integrality. As can be seen in Fig. 5(c), many pore spaces had been produced and uniformly distributed in the substrate. There were some skeleton particles observed in WDC10 substrate, but they were few, indecipherable clear, and their combination with debris particles was poor. It seemed that the debris particles area and part of the surface of skeleton particles were covered by a layer of floccule, presenting a flocculate-like structure in VC substrate. The former may be due to the failure of bonding between debris particles; the latter is for the peeling and covering of the debris particles cemented on the surface of skeleton particles, which is also due to the bonding loss between solid particles.

Based on the analysis, wetting and drying cycles can do damage to the structure of VC substrate and change its structure from cemented dense state to loosen state. Hence, the weakening of the bond between solid particles was the predominant aspect of the damage to the VC substrate caused by wetting and drying cycles. This bond loss is what leads to the weakening deviator stress-strain behavior and reduction in the strength parameters of VC substrate as manifested in Fig. 3 and Fig. 4. This can also adequately explain the reduction in cohesion. It is worth noting that the pore size in WDC10 substrate does not change much compared with that in WDC5, which may be due to the filling or covering of the tiny floccule as mentioned above.

The ultrasonic wave method is a non-destructive way to measure structural damage and is widely used to analyze the damage evolution of soils. In this study, ultrasonic waves of the substrate labeled WDC0-10 were measured and a damage variable D which was described by Gong et al. (2018) was defined using the following formula.
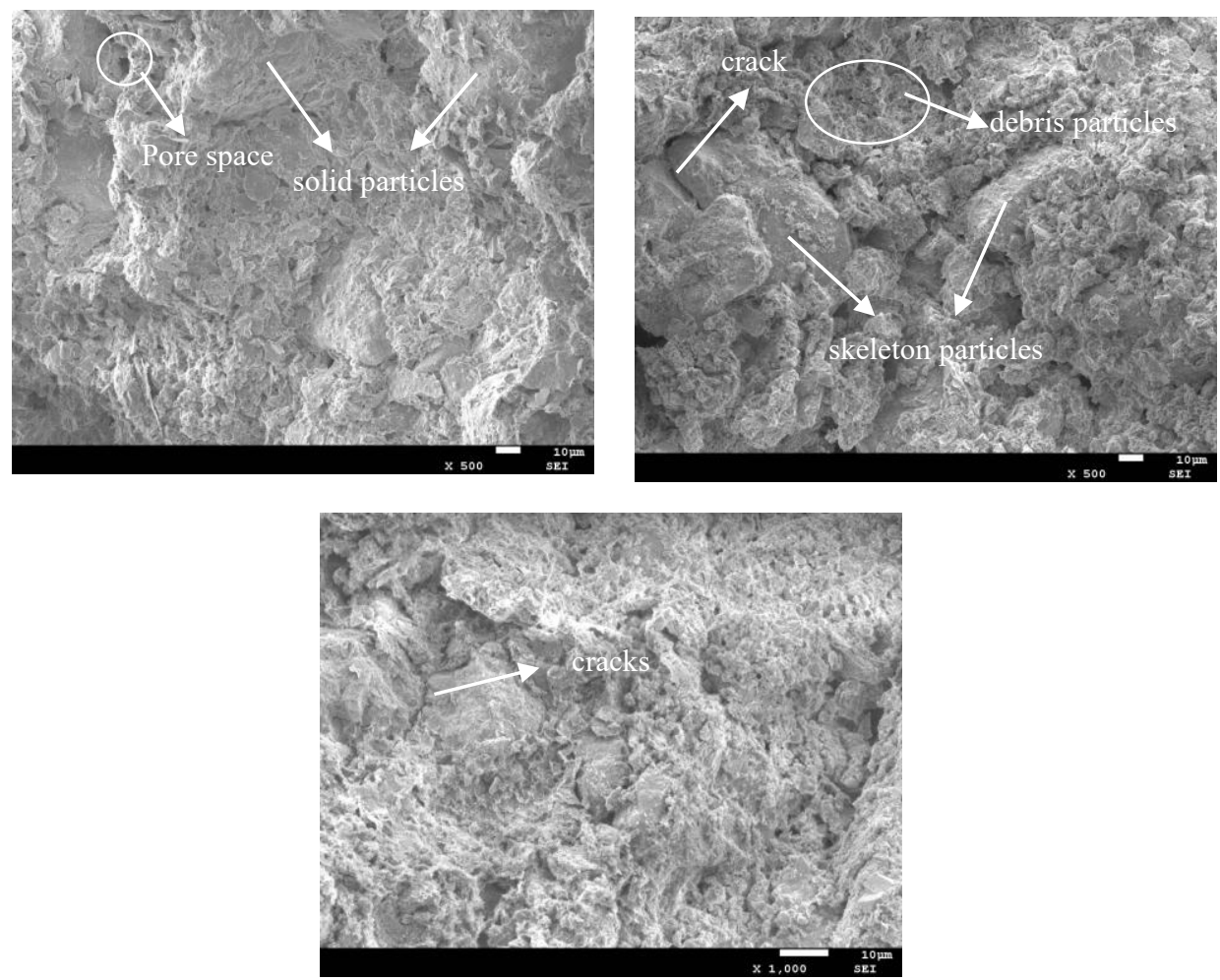

Fig. 5: SEM micrographs of (a) WDC0 substrate; (b) WDC5 substrate; and (c) WDC10 substrate. 


$$
\mathrm{D}=1-\left(\mathrm{V}_{\mathrm{T}} / \mathrm{V}_{0}\right)^{2}
$$

Where, $\mathrm{D}$ is the structural damage variable; $\mathrm{V}_{\mathrm{T}}$ is the ultrasonic wave velocity of the WDC0-10 substrate with $\mathrm{n}$ times of wetting and drying cycles $(0<\mathrm{n}<10$, and $\mathrm{n}$ is an integer); the value of $\mathrm{V}_{0}$ is equal to $0.662 \mathrm{~km} . \mathrm{s}^{-1}$.

Fig. 6 shows the relationship between the structural damage variables and times of wetting and drying cycles. It can be seen that the structural damage variable (D) increases nonlinearly as the number of wetting and drying cycles (n) increases, with a slowing rate of increase. This shows that structural damage accumulates as the number of wetting and drying cycles increases and that this cumulative behavior becomes less obvious as the cycles continue (Pineda et al. 2014).

The dynamics change of D during wetting and drying cycles was well described by a semi-logarithmic relationship with a coefficient correlation of 0.90 , as shown in formula (2).

$$
\mathrm{D}=0.1686 \ln (\mathrm{n})+0.1976
$$

The semi-logarithmic fitting is compatible with the results of a similar experiment conducted by Wei et al. (2015) on expansive soil, proving that this method is feasible for $\mathrm{VC}$ substrate. In practice, of course, this function combined with the SEM micrographs, as shown in Fig. 5, gives a reference for relevant researchers and engineers to evaluate the damage degree of VC substrate: the VC substrate possesses the partial cementing state when the structural damage variable ranges from 0 to 0.4 ; however, when the structural damage variable is beyond 0.6 , it will be in a loose state. In Fig. 6, though the structural damage variable $\mathrm{D}$ at 10 times of wetting and drying cycles was highest, it does not represent the most severe damage state for $\mathrm{VC}$ substrate, because within the times of the wetting and drying cycles in this study, the structural damage variable D was still in a slightly upward trend and had not reached steady state. This indicates that the VC substrate at 10 cycles was not completely destroyed, this notion is confirmed by the existing skeleton particles in Fig. 5 (c).

Relationships between Strength Loss and Structural Damage: Studies have shown that strength change of soil is a macro-reflection of the microstructural damage. In this research, the internal relations of strength loss and structural damage can provide a theoretical basis for mechanical properties of $\mathrm{VC}$ substrate under wetting and drying cycles, and it is also popularized in other damage factors. For this purpose, the strength loss rate was defined to evaluate the degree of strength reduction (Gong et al. 2018), as shown in the following formula $(3) \sim(5)$ :

$$
\begin{gathered}
\Delta \mathrm{q}_{\max }=1-\mathrm{q}_{\max } / \mathrm{q}_{\max 0} \\
\Delta \mathrm{q}_{\mathrm{res}}=1-\mathrm{q}_{\mathrm{res}} / \mathrm{q}_{\mathrm{res} 0} \\
\Delta \mathrm{C}=1-\mathrm{C}_{\mathrm{T}} / \mathrm{C}_{0}
\end{gathered}
$$

Where, $\Delta \mathrm{q}_{\max }, \Delta \mathrm{q}_{\text {res, }}$ and $\Delta \mathrm{C}$ are the peak strength loss rate, residual strength loss rate, and cohesion loss rate; $q_{\max 0}$, $\mathrm{q}_{\text {res} 0}$, and $\mathrm{C}_{0}$ are the values of the peak strength, residual strength, and cohesion of the substrate WDC0; $\mathrm{q}_{\max T}, \mathrm{q}_{\mathrm{res} T \text {, }}$ and $\mathrm{C}_{\mathrm{T}}$ are the values of the peak strength, residual strength, and cohesion of the substrate WDC5 or WDC10, respectively. It is noted that the friction angle of the VC substrate was analyzed here because the impact of wetting and drying cycles on it had not been found in this study.

Fig. 7 shows the relationships between the strength loss rate and structural damage variables of VC substrate. It was found that the strength loss rates of peak strength, residual strength, and cohesion were linearly correlated with the structural damage variables, and the fitted effect was preferable. The fitting results obtained were consistent with the findings concluded by Wang et al. (2016).

\section{Damage Mechanism of Wetting and Drying Cycles}

The microstructural damage or macro-strength reduction of soil matrixes during wetting and drying cycles are usually

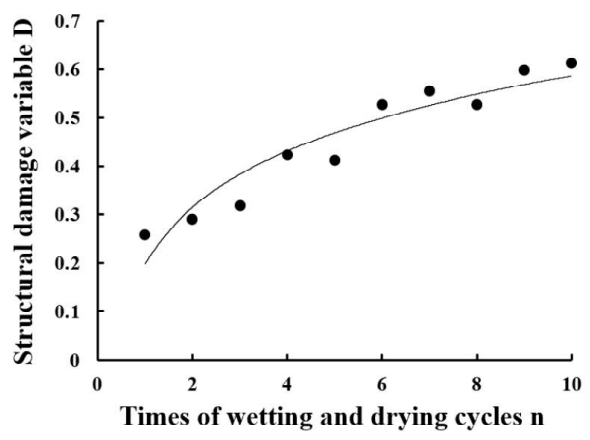

Fig. 6: Damage variables of VC substrate. 
associated with the water-physical properties of their components. In this section, we will discuss the relevant properties in the aspects as follows.

Minerals: Hydrophilic minerals are usually considered to be a disadvantage factor as they extensively exist in natural soils and can expand or contract when the moisture content of soil changes (Deng et al. 2017). The expansion and contraction deformation of hydrophilic minerals may result in compression and tension between the contact surfaces of solid particles and thereby weaken the bond between soil particles. As the wetting and drying cycles continue, the compression and tension take place alternately in time and continue to repeat one another. These cyclic stresses in the soil will eventually lead to damage to soil structure or weakening of mechanical properties at a macro level (Muntaha 2017).

As listed in Table 2, the VC substrate contained two kinds of hydrophilic minerals: montmorillonite and illite with a total content of $18 \%$ by weight, which were also the only two clay minerals in VC mixtures. Because montmorillonite and illite have high hydrophilicity, they can expand and contract significantly in volume during wetting and drying cycles, and because they were the primary clay cementing materials for solid particles in the VC substrate, their effects on structural damage would manifest as a weakening of the soil-particle bond, as shown in Fig. 5. In addition, it is worth noting that the content of montmorillonite and illite measured by the XRD method was much higher than that of the clay particles but less than $0.074 \mathrm{~mm}$ in the particle analysis test, as shown in Table 1. This indicates that part of montmorillonite and illite minerals existed in bigger solid particles and their expansion and contraction deformation during wetting and drying cycles may be the reason for the cracks in skeleton particles. Furthermore, the VC substrate is an alkaline cemented soil and its $\mathrm{pH}$ value can reach 12 . We cannot rule out the possibility that quartz and albite might dissolve in alkali solution and accelerate soil structural damage as Qiu et al. (2007) reported.

Sawdust: Sawdust is the second-largest component of VC substrate, and its content was high up to $28.35 \%$ by volume. As a kind of woody material, sawdust has the properties of
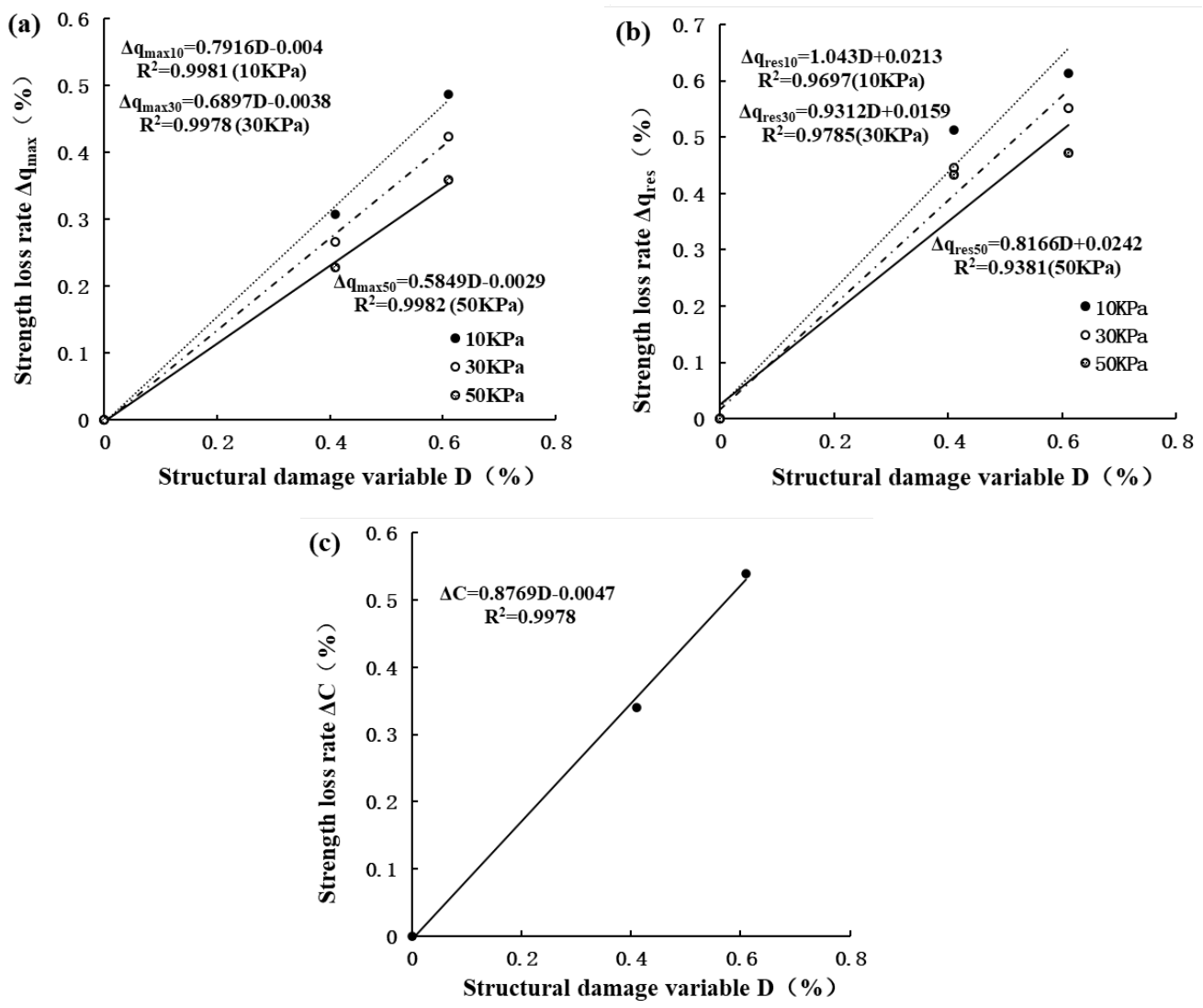

Fig. 7: Relationship between strength loss rate and damage degree of VC specimens. (a) peak strength loss rate; (b) residual strength loss rate; (c) cohesion loss rate. 
wet-swelling and dry-shrinkage. When the moisture content is below the fiber saturation point, woody materials may expand in volume after absorbing water and shrink after losing water. This swelling and shrinkage deformation have more or less the same impact on soil structure as hydrophilic minerals do. To further diagnose the possibility of this volumetric deformation of sawdust during wetting and drying cycles, the water content of sawdust was measured before wetting. The test result showed that its water content before wetting (or at the end of drying) was $8.53 \%$, which was significantly lower than the average fiber saturation point of woods in China, as 28\% reported by Ai and Zhang (2016). This indirectly confirmed that sawdust could cause damage to the soil structure.

In general, the structural damage of VC substrate during wetting and drying cycles was a comprehensive effect by the expansion and contraction of hydrophilic minerals, as well as the swelling and shrinkage of the sawdust. It should note that the structural damage of VC substrate can also be accelerated by matric suction during wetting and drying cycles.

\section{CONCLUSION}

This research was conducted to further our understanding of the durability of the VC substrate under wetting and drying cycles. Based on the findings and results, the following main conclusions can be drawn:

(1) Wetting and drying cycles affected the features of the strain-stress curves of the VC substrate. Compared with the control substrate WDC0, the initial compaction property of the WDC10 substrate was more pronounced and the initial slope and deviatoric stresses were low. It was also found that the relevant properties of the WDC5 substrate were at an intermediate level between WDC0 and WDC10 substrate.

(2) The peak strength, residual strength, and cohesion of the WDC10 substrate were decreased by more than 40-percent, 60-percent, and 50-percent, respectively. The corresponding decrease for the substrate WDC5 was about 20-percent in peak strength, 50-percent in residual strength, and 30-percent in cohesion. However, no influence was found on friction angle.

(3) The weakening of the bond between solid particles was the predominant aspect of the damage to the VC substrate caused by wetting and drying cycles. The actions of wetting and drying cycles ultimately made the VC substrate change from a dense matrix to a loose matrix with plenty of pore space.

(4) The structural damage of VC substrate accumulated with the increase of the times of wetting and drying cycles, but at a slower rate, and it followed a semi-logarithmic function. And it was found that the strength loss rates of VC substrate increased linearly with the structural damage variable.

(5) The mechanisms actions of wetting and drying cycles on structural damage or mechanical properties of VC substrate include the expansion and contraction of hydrophilic minerals, the swelling and shrinkage of the sawdust, and the driving effects of the matric suction.

\section{ACKNOWLEDGEMENTS}

This research was supported by the National Key Research and Development Program of China (Grant No. 2017YFC0504902-05), the National Natural Science Foundation of the People's Republic of China (Grant Nos. 51979147 and 51678348), the Natural Science Foundation of Hubei Province (Grant Nos. 2016CFA085 and 2017ACA189), and the Research Fund for Excellent Dissertation of China Three Gorges University (2019BSPY006).

\section{REFERENCES}

Ai, M.Y. and Zhang, X.F. 2016. Practice and application for wood drying. Chemical Industry Press, pp. 6-9.

Deng, H.F., Fang, J.C., Li, J.L., Xiao, Y. and Zhou, M.L. 2017. Mechanical properties of red-bed soft rock on the saturated state. J. China Coal Soc., 42(8): 1994-2002. (in Chinese)

Gong, J.Q., Deng, G.Q. and Shan, B. 2018. Ultrasonic test and microscopic analysis of reactive powder concrete exposed to high temperature. J. Hunan Univ. (Nat. Sci.), 45(1): 68-76. (in Chinese)

Hayano, K., Dong, P.H. and Morikawa, Y. 2013. Physical and mechanical properties of cement-treated granular soils with respect to the geotechnical application. AIP Conf. Proceed., 1542: 301-304.

Liu, D.X., Zhang, B.H., Yang, Y.S., Xu, W.N., Ding, Y. and Xia, Z.Y. 2018. Effect of organic material type and proportion on the physical and mechanical properties of vegetation-concrete. Adv. Mater. Sci. Eng., 7(3): 1-8.

Muntaha, M. 2017. The effect of drying-wetting cycle's repetition to the characteristic of natural and stabilization residual soils Jawa Timur-Indonesia. IOP Conf. Series-Mater. Sci. Eng., 267: 012030.

Pineda, J.A., Romero, E., Gracia, M.D. and Sheng, D. 2014. Shear strength degradation in claystone due to environmental effects. Geotechnique, 64(6): 493-501.

Qiu, L.W., Zhao, W. and Liu, K.Y. 2007. Alkali diagenesis and its application in Jiyang Depression. Petrol. Geol. Recov. Efficiency, 14(2): 10-15. (in Chinese)

Sayem, H.M., Kong, L.W. and Yin, S. 2016. Effect of drying-wetting cycles on saturated shear strength of undisturbed residual soils. Amer. J. Civil Eng., 4(4): 143-150.

Tan, W.C. and Chen, P.H. 2014. Study on characteristics of cement-modified expansive soil under drying-wetting cycles. Hunan Comm. Sci. Technol., (3): 34-35. (in Chinese)

Wei, B.X., Huang, Z. and Yang, J. 2015. Research on the relationship between shear strength and damage variable of expansive soil based on wave velocity. J. Highway Transp. Res. Dev., 32(6): 39-45. (in Chinese)

Wang, H.X., Ke, R., Tan, Y.Z., Wu, J. and Huang, L.B. 2018. Deterioration characters of solidified/stabilized sediments by dry-wet circulations. Bull. Chinese Ceramic Soc., 37(9): 2704-2709. (in Chinese) 
Wang, Y., Li, X. and Zheng, B. 2016. Experimental study on mechanical properties of clay soil under compression by ultrasonic test. Eur. J. Environ. Civ. Eng., 5: 1-20.

Wang, T., Weng, X.Z., Zhang, J., Jiang, L., Liu, P.C. and Zhang, S. 2017. Strength characteristics of fiber-reinforced solidified sand under dry-wet cycles. J. Railw. Sci. Eng., 14(4): 721-729. (in Chinese)

Xu, W.N. and Wang, T.Q. 2001. A Kind Of Greening Agent Used for Vegetation-Growing Concrete. P. China. Beijing, China

Yu, X.J. 2012. Test study on engineering properties of low liquid limit lilt and improved soil under wetting-drying cycle. J. Shijiazhuang Tiedao
Univ. ( Nat. Sci.), 25(1): 86-94. (in Chinese)

Yang, J., Yang, Z., Zhang, G.D. and Tang, Y.W. 2014. Influence of shear rate and lime-ash content on shear strength index of weathered sand. J. Lanzhou Univ. Technol., 40(5): 126-130. (in Chinese)

Zhang, J. 2018. Experimental study on compressive strength and durability of polypropylene fiber reinforced cemented soil under drying and wetting cycles. J. China Foreign Highway, 38(6): 235-238. (in Chinese)

Zhang, Z.H., Jiang, Q.H., Zhou, C.B. and Liu, X.T. 2014. Strength and failure characteristics of jurassic red-bed sandstone under cyclic wetting-drying conditions. Geophys. J. Int., (2): 1034-1044. 